\title{
The Dakota Father Friendly Assessment: Measuring Father Friendliness in Head Start and Similar Settings
}

Article in Fathering A Journal of Theory Research and Practice about Men as Fathers · March 2011

DOI: 10.3149/tth.0901.22

CITATIONS

5

5 authors, including:

Sean E. Brotherson

North Dakota State University

44 PUBLICATIONS 296 CITATIONS

SEE PROFILE

Erin K. Holmes

Brigham Young University - Provo Main Campus

61 PUBLICATIONS 745 CITATIONS

SEE PROFILE
READS

362

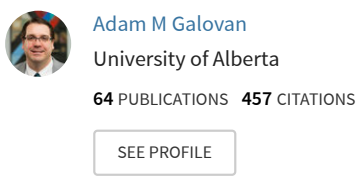

Some of the authors of this publication are also working on these related projects:

Work-family conflict View project

Future Directions of Relationship and Marriage Education View project 


\title{
The DAKota FATHER Friendly AsSessment: MEASURING FATHER FRIENDLINESS IN HEAD Start AND Similar SetTings
}

\begin{abstract}
Head Start programs offer a setting to examine support that facilitates father involvement. The Dakota Father Friendly Assessment (DFFA) is designed to evaluate an organization's level of father-friendliness. To establish its psychometric properties, a sample of North and South Dakota early childhood staff $(\mathrm{N}=609)$ completed the DFFA. A number of measures were included as indicators of validity. Factor analysis of the DFFA confirmed the presence of four expected factors and revealed a fifth factor (loadings ranged from .40 to .80). Coefficient alphas for DFFA subscales ranged from .71 to .87. Moderate relationships existed between DFFA subscales and other measures, demonstrating concurrent and discriminant validity. Research is needed to determine the efficacy of the DFFA in other organizational settings and to identify change over time.
\end{abstract}

Keywords: father friendly organizations, responsible fatherhood, father measurement, father friendly scales, fathering, Head Start male involvement programs

Research spanning three decades has established that active, positive fathering is good for children and fathers (Lamb, 1975; Lamb, 2004). Father involvement has been correlated with infant secure attachment (Notaro \& Volling, 1999), toddler ability to regulate negative feelings (Davidov \& Grusec, 2006), higher self-esteem in middle school (Amato, 1987), and higher school achievement in adolescence (Ramirez-Valles, Zimmerman, \& Juarez, 2002). Father involvement also promotes men's healthy de-

\footnotetext{
a President, Foundation for Family Life.

${ }^{b}$ Dept. of Human Development and Family Science, North Dakota State University.

c Department of Human Development and Family Studies Graduate Program, University of Missouri-Columbia.

d School of Family Life, Brigham Young University.

e Early Childhood Education, South Dakota State University.

Correspondence should be addressed to Joseph M. White, Ph.D., Foundation for Family Life, 1733 W. 12600 S., \#230, Riverton, UT, 84065. Email: joseph.familylife@gmail.com
} 
velopment. When men engage with their children, they gain a stronger sense of purpose in life (Palkovitz, Copes, \& Woolfolk, 2001), increase intergenerational and extended family interaction (Knoester \& Eggebeen, 2006), and report increased job performance (Graves, Ohlott, \& Ruderman, 2007).

But strengthening father-child relationships to promote healthy outcomes for children and fathers does not occur without effort (Brotherson \& White, 2007). Fathers, as well as mothers, often need support to know how to parent well (Berger, 1995). Children need opportunities to interact with fathers or father figures to strengthen these bonds too (Lamb \& Lewis, 2004). A recent meta-analysis of community fathering programs presents direct evidence that providing services to resident fathers increases father's day-to-day care for children, improves coparenting, improves the quality of the father-child relationship, and minimizes child behavior problems (Holmes, Galovan, Yoshida, \& Hawkins, 2010). Though the samples from which this meta-analysis were drawn primarily include middle-income white fathers, results from low-income, multiethnic, and non-resident samples also provide direct evidence that giving resident and non-resident fathers support will improve fathering outcomes (see for example, Cowan, Cowan, Pruett, Pruett, \& Wong, 2009; Fagan, 2008). Based on the accumulation of such evidence, early childhood educators seek ways to improve father involvement through partnerships with parents, early childhood programs, and the community. To this end the Head Start Father/Male Involvement Initiative implemented the following program goals: strengthen men's roles in families, increase men's participation in the program, strengthen father-child relationships, and create opportunities that facilitate father-child interaction (Fagan \& Iglesias, 1999; McBride \& Lutz, 2004).

Unfortunately, facilitating father involvement in early childhood settings can be stalled if the program is not "father friendly" (McBride \& Rane, 1996). What is a "father friendly" program? "Father friendly" programs value father involvement with young children. To get fathers involved, father friendly programs assess staff members' attitudes about men, train staff members to consider the myths versus realities of their attitudes, encourage staff members to get to know fathers/father figures, create environments that welcome men, and try to recruit male staff (Cunningham, 2000). These efforts promote positive father involvement by encouraging fathers to participate in early childhood settings and by helping men feel a valuable part of the program (Cunningham; McFarland, 2000). Thus, Head Start and other similar programs can benefit from the systematic assessment of the father friendly environment of the program.

The goal of this paper is to present and examine the psychometric properties of a father friendly assessment tool (Dakota Father Friendly Assessment or DFFA) to determine its reliability, validity, and utility. We begin with a theoretical framework for our work, review the literature on staff attitudes as correlates of father involvement, establish that a tool is needed for assessing staff and organizational attitudes and behaviors, describe the development of our tool, and suggest implications for establishing fathersupportive policies and practices in Head Start and other early childhood settings. 


\section{Becoming Father-Friendly in Head Start and Similar Settings}

\section{Theoretical Framework}

Based on Bronfenbrenner's (1986) ecological theory, early childhood educators emphasize the interplay between children, parents, practitioners, and the social environment. Ecological theory assumes that individuals develop in a multitude of systemic contexts: the microsystem, mesosystem, exosystem, and macrosystem. The two systems most relevant to the role of early childhood settings are the microsystem, which encompasses the relationships and interactions a father and child have with their immediate surroundings (e.g., the interaction between father and child at home), and the mesosystem, which represents the connection between the individual and the institutions with which s/he interacts (e.g., the connection between early childhood educators and children or fathers). Thus, guided by this framework, fathers and children should be able to improve interaction with each other when father-child interaction is also facilitated in the child's early care setting.

\section{Father Involvement in Early Childhood Programs}

Involving parents in the educational process is a central premise in Head Start's approach to early childhood education (Castro, Bryant, Peisner-Feinberg, \& Skinner, 2004; Zigler \& Styfco, 2000). Ecological theory (Bronfenbrenner, 1986) claims that when parents are aware of an educator's goals for the child, parents will be more likely to support those goals in the educational setting and at home. The theory further claims that when educators interact regularly with parents, educators will be more aware of parents' personal goals for the child, and can be more supportive of parents efforts while the child is in school. Ultimately, this interaction between parents and educators can lead to stronger child developmental outcomes. Surprisingly, despite research supporting the benefits of parental involvement, and the Head Start performance standards' emphasis on parental involvement, Castro and colleagues note that "Head Start programs face many challenges in trying to increase the number of parents who actively participate in Head Start activities" (p. 414). Raikes and Bellotti (2006), however, note that the majority of the research and early intervention work has focused primarily on mothers and their children. An additional challenge then, is to develop policies and practices that will encourage not just mothers, but also fathers, to be involved in program activities. By necessity, then, such efforts will involve encouraging program staff to engage fathers more fully in the program.

What influences fathers' participation in early childhood settings? Researchers have established that parental skills, maternal engagement in the program, parent and teacher educational level, child gender, and maturity of father involvement efforts in a program affect fathers' participation (Fagan, 1999; Raikes, Summers, \& Roggman, 2005). Levine (1993) also established four factors which may constrain father involvement in early childhood settings, (1) fathers' fears of exposing inadequacies, (2) ambivalence 
of staff members about father involvement, (3) maternal gatekeeping, and (4) inappropriate program design and delivery. Note that two of the four factors identified by Levine link directly to staff attitudes and behaviors (ambivalence of staff, program design and delivery). The other two indirectly affect staff attitudes and behaviors (gatekeeping and fathers' concerns). Because program efforts to involve fathers depend on staff members' attitudes about and behaviors toward involving fathers with young children, it is critical to find meaningful ways to assess attitudes and behaviors that either hinder or support the father friendliness of a program.

\section{Staff Members and Father Involvement}

Articles addressing father involvement in Head Start settings typically furnish implications for program operations, assuming that program staff will be the key personnel to carry out specific efforts or recommendations (Fagan, Newash, \& Schloesser, 2000; Raikes et al., 2002; Raikes et al., 2005). However, little attention has been paid to the underlying feelings, attitudes, and behaviors of staff members who are asked to focus on father involvement as a program priority. McBride and colleagues (2001) created an intervention focused on helping staff members receive the necessary knowledge "to successfully plan, implement, and evaluate specific initiatives to encourage father/male involvement in their program" (p. 80). They observed that the initial low participation of men/fathers at their intervention site was due to "a lack of knowledge, skills, and opportunities on the part of staff members" (p. 81) rather than lack of interest from fathers and families themselves.

McAllister and colleagues (2004) note that staff attitudes, experiences, and resources are a main set of barriers to father involvement in Head Start. Staff members interact with children, serve families, and harness the resources of an organization. According to an ecological theoretical approach, staff members facilitate interaction within the mesosystem by creating connections between individuals and the institution. Thus, if staff members do not invest in the value of father involvement in their program, little will be done to facilitate father involvement with the institution. A greater awareness of what staff members think and feel about father involvement in early childhood settings could focus a program's efforts. Fagan (1999) developed an intervention program to support father involvement that included training for staff members in working with fathers, and found a significant treatment group difference in involvement for fathers supported by staff running the intervention program than for fathers not so involved. With continuing commitment to the ideal of father involvement in Head Start and other early childhood settings (Horn, 2004), increasing awareness of staff members' perspectives and behaviors regarding father involvement through empirical assessment can enhance our efforts to be father-friendly in early childhood settings.

\section{Assessment of Father Friendliness: A Critically Needed Tool for Program Success}

While scholars have argued for the need to engage staff, understand their views, and work to lower barriers when implementing father-friendly efforts in early childhood 
settings (Fagan et al., 2000; McAllister et al., 2004), very little research has been done to create and evaluate assessment tools of father friendliness. Programs desiring to identify and resolve barriers to father friendliness need a systematic approach to gathering and exploring information about staff and organizational attitudes, behaviors, and needs. The best assessment tools will have a solid grounding in both research and practice (McBride \& Lutz, 2004).

We located three assessment tools representing early steps taken by scholars to measure staff attitudes about father involvement: the Attitudes Toward Father Involvement Scale (ATFI), the Role of the Father Questionnaire (RFQ), and Father-Friendliness Organizational Self-Assessment and Planning Tool, available from the National Head Start Association.

The ATFI is part of a 13-item scale (General Attitudes Toward Parent Involvement; Garinger \& McBride, 1995) and consists of 6 items on a 5-point Likert type scale. Internal consistency for the ATFI was good $(\alpha=.76)$. The Role of the Father Questionnaire (RFQ; Palkovitz, 1984) consists of 15 items initially designed to explore mothers' and fathers' beliefs about men's roles and capacities as parents, but it was used by Fagan and colleagues (2000) to ask female caregivers their perceptions about the involvement of men with Head Start children. This measure has established reliability with residential parents (Palkovitz, 1984), non-residential parents (Fagan \& Barnett, 2003), and female caregivers (Fagan, 2000). Both the ATFI and RFQ measures are short, empirically based tools that highlight attitudes toward fathers and their involvement, and provide a good foundation for further exploration with staff members. However, because they are brief and were designed for other purposes, they offer little information on staff behaviors, organizational attitudes, and organizational behaviors. Not only do social scientists recognize that attitudes and behaviors are distinct, but organizational behavior research also establishes that human behavior is influenced by the attitudes and behaviors of others in an organization (George \& Jones, 2008). These attitudes and behaviors can establish trends that evolve into a type of organizational subculture that permeates much of what occurs in that setting. Because an organization is a complex system with specific rules, goals, and roles, attitudes and behaviors found in an organizational setting will influence individual attitudes and behaviors.

Perhaps the closest tool designed for assessing father-friendliness in early childhood settings is the Father-Friendliness Organizational Self-Assessment and Planning Tool, available from the National Head Start Association (Vann \& Nelson-Hooks, 2000). While this tool for program assessment does allow early childhood programs to ask questions about staff and organizational attitudes and practices, no information (published or non-published) about the empirical validity, reliability, or use of the tool is provided. A more comprehensive assessment tool is needed, one that provides detail specific to staff attitudes, staff behaviors, organizational attitudes, and organizational behaviors. Evaluation allows one to systematically test what works and does not work to promote father friendliness in one's program. The most effective assessment tools are those subjected to rigorous evaluation establishing that the items yield reliable, valid, and useful results (Holmes et al., 2010). 


\section{The Dakota Father Friendly Assessment Tool}

Given the lack of empirically based assessment tools for father-friendliness, we developed a new measure for use both in research and practice to gauge and track fatherfriendliness in early childhood settings. The Dakota Father Friendly Assessment (DFFA) is designed to enable scholarly exploration of father-friendliness in early childhood settings, allow programs to better understand the views and activities of staff members toward father involvement, and provide a mechanism for gathering empirical and baseline data that programs can use in establishing goals for program improvement. With limited assessment tools to aid organizations in becoming more father-friendly, the DFFA should be a welcome addition to the assessment field. This paper will explore the psychometric properties of the DFFA to determine its reliability, validity, and utility as a father-friendliness assessment tool.

\section{METHODS}

\section{Procedures}

Questions for the Dakota Father Friendly Assessment (DFFA) were developed by a research team at South Dakota and North Dakota State Universities through an extensive review of the literature and analysis of available instruments related to fathering that existed in the field. The questions were also reviewed and approved by local Head Start site directors and participants of the respective state Head Start Association Boards. Development of the father-friendly assessment tool resulted in an initial 55item measure consisting of four subscales. Additional measures were included in the overall survey for research and evaluation purposes. Head Start administrators at 20 sites in North and South Dakota were contacted and given careful instructions on administering the survey. Surveys were sent out to Head Start program leaders who disseminated them to directors, staff, and teachers. All staff and administrators were asked to complete the anonymous questionnaire and return it to the person coordinating the project on their site in a confidential manner. Surveys were then returned to the research team and entered into a database for statistical analyses.

\section{Participants}

A total of 1020 surveys were sent to administrators in specific geographically-defined (Region VIII) and group-defined (Region XI-tribal) regional Head Start program sites in North and South Dakota. The federal Office of Head Start divides a collection of program sites by region in order to provide specific training and guidance from regional offices that may be more specific to that area of the country (e.g., rural vs. urban, etc.). That number was the total of the initial estimates provided by administrators to the researchers. Surveys were handed out during "all staff" training sessions in which all staff were invited to attend and participate. However, conflicts due to scheduling, 
covering classes, sickness, or other reasons, precluded all staff from attending these sessions and administrators tended to overestimate the number of surveys needed. Verbal and written reports from administrators indicated that nearly 100 percent of all staff present completed the surveys. During data cleaning, a few surveys with substantial missing data were removed from analysis (there were not enough to conduct missing data analysis). With 609 usable surveys in our final dataset, we are confident that the surveys were representative of all staff and administrators in both Region VIII and Region XI. While we recognize there may be a selection bias among those who did not attend the trainings and were thus not able to complete the survey, this bias presents little concern as the purpose of this paper is to present the psychometric properties of a new tool for use in these settings.

Head Start and Early Head Start staff respondents were 39 years old on average (ranging in age from 19 to 67), primarily female (97\%), and have worked in the organization for an average of 5 years (ranging from 1 month to 30 years). About 70 percent of staff respondents were direct service providers (e.g., teachers, bus drivers, cooks, or other support staff) and 30 percent were in management positions. Ethnicity of the participants included 91 percent Caucasian, 6 percent American Indian, and 3 percent other. Finally, one third (31\%) had children in Head Start at one time or another and 64 percent were currently married.

\section{Measures}

Several measures were incorporated into this study in order to validate findings from the Dakota Father Friendly Assessment (DFFA). In addition to a basic demographic questionnaire, we utilized the Role of the Father Questionnaire (RFQ; Palkovitz, 1984), the General Attitudes Toward Parent Involvement scale (GATPI; Garinger \& McBride, 1995), the Kansas Marital Satisfaction Scale (KMSS; Schumm et al., 1986), the Fatherwork Scale, and the Connectedness with Father Scale (developed based on Head Start staff request). All scales used had a 5-point Likert response option ranging from "Strongly Disagree" $=1$ to "Strongly Agree" = 5 (with the exception of the CFS and KMSS). Coding for all measures are presented so that higher scores reflect more favorable responses.

Dakota Father Friendly Assessment. The DFFA was developed for use with organizations, particularly in early childhood settings, that directly or indirectly interact with fathers and father figures associated with the families they serve. This tool needed to measure "staff perceptions about" father involvement rather than "level of" a father's involvement. We identified four distinct areas of staff perceptions regarding father involvement, including perspectives on their own attitudes and behaviors as well as their perspectives on organizational support for father involvement. The 55 items developed for this survey were drawn from the literature and were designed to fit into one of these four areas.

Sample items from the four DFFA subscales (Staff Attitude [SA], Staff Behavior [SB], Organizational Attitude [OA], Organizational Behavior [OB]) include: "Fathers 
bring unique strengths to parenting that meet a child's growth and development needs" (SA), "I make an effort to have fathers sign family partnership agreements" (SB), "Staff should have a positive attitude toward working with fathers" (OA), and "Head Start provides regular training on father involvement (at least semiannually)" (OB). The original DFFA subscale average scores and Cronbach's alpha coefficients were $S A$ : 3.84 (SD $=.32)$, alpha $=.72 ; S B: 3.86(S D=.43)$, alpha $=.82 ; O A: 3.89(S D=.32)$, alpha = .80; $O B: 3.52(S D=.47)$, alpha $=.81$. Following is a description of the original four DFFA subscales that have been used in a variety of settings across the Midwest (White, 2005, 2006; White et al., 2003).

Staff Attitudes items are intended to assess how individual staff members perceive and think about aspects of father involvement. Staff who are supportive of father involvement may be more likely to follow through and make efforts to engage fathers in positive ways. Staff Behaviors items are meant to assess how staff behave relative to father involvement at the individual level. These measures of individual behaviors tend to indicate how people are engaged in actual "father-friendly" actions that shape the atmosphere for male involvement and provide a positive, inviting approach to being involved. Organizational Attitudes is intended to assess perceptions of overall Head Start staff and administrative attitudes relative to father involvement. These perceptions of overall staff demeanor provide a profile of the "organizational culture" related to father involvement. Organizational Behaviors is an indicator of actual Head Start staff and administrator father involvement activities and behaviors. This subscale provides insight into the level of support provided by the Head Start program to assist staff members in their efforts to facilitate father involvement, the existence of specific program efforts to reach out or support fathers, and facilitation of specific behaviors intended to support and encourage father involvement.

Role of the Father Questionnaire. Additional measures were included to provide evidence of construct validity. The 10-item Role of the Father Questionnaire (RFQ; Palkovitz, 1984) was included to tap into staff perspectives about the various roles fathers can play in raising their children and has reported good internal consistency elsewhere with reliability coefficients of .77 (McBride \& Rane, 1996). A sample item from the RFQ is "It is as important for a father to meet a baby's psychological needs as it is for the mother to do so." Responses were given on a 5 point scale ranging from "Strongly Disagree" = 1 to "Strongly Agree" = 5. The mean RFQ score was 4.10 (SD $=.46$ ) with a Cronbach's alpha coefficient of 79 in the current study.

Attitudes Toward Father Involvement scale. Six items from the General Attitudes Toward Parent Involvement scale (GATPI) were included as the Attitudes Toward Father Involvement scale (ATFI) (Garinger \& McBride, 1995). These items focused directly on father involvement and have reported a reliability coefficient of .76 (McBride \& Rane, 2001). A sample item from the ATFI is "Most fathers of children enrolled in Head Start are not that interested in parent involvement" (reverse coded). The average ATFI score was $3.79(S D=.54)$ with a Cronbach's alpha coefficient of .73 . 
Fatherwork Scale. The 14-item Fatherwork Scale provides basic insight into perspectives about the seven aspects of the generative fathering framework (Hawkins, Dollahite, \& Brotherson, 1997) and highlights the value placed on fathering rather than viewing fathering from a deficit perspective (Hawkins \& Dollahite, 1997). Sample items from the FWS include: “Father play' tends to promote initiative and independence in children" and "Many fathers work to create opportunities for their children to grow and achieve." The average FWS score was $4.21(S D=.39)$ with a Cronbach's alpha coefficient of .82 .

Connectedness with Father Scale. Finally, the three-item Connectedness with Father Scale (CFS), developed for use with this survey based on Head Start staff request, explores the influence that staff relationships with their own fathers may have on their perspective toward the fathers with whom they currently work. A sample item from the CFS is "How emotionally close are/were you with your father?" Responses were on a 5 point scale ranging from "Not at All" $=1$ to "A Great Deal" $=5$. The average CFS score was $3.94(S D=1.00)$ with a Cronbach's alpha coefficient of .91 .

Kansas Marital Satisfaction Scale. The three-item Kansas Marital Satisfaction Scale (KMSS; Schumm et al., 1986) measures an individual's level of satisfaction with his or her current or previous marital relationship (if divorced or separated). We also included this measure to assist in establishing discriminant validity. The KMSS has demonstrated good internal consistency (.93) and adequate test-retest reliability (.62 .72) (Schumm et al., 1986). A sample item from the KMSS is "How satisfied are you with your marriage?" Response options for the KMSS were on a 7 point scale ranging from "Extremely Dissatisfied" $=1$ to "Extremely Satisfied" $=7$. The average KMSS score in this study was $5.62(S D=1.56)$ with a Cronbach's alpha coefficient of .98 . Each of these measures provides opportunity for comparative analysis with the DFFA and exploration of its potential value and usage in early childhood settings.

\section{RESULTS}

The goal of this paper is to examine the psychometric properties of the DFFA to determine its reliability, validity, and potential utility as a father-friendliness assessment tool. To this end, we conducted a factor analysis of the 55 DFFA items in an effort to identify clear, consistent factor structures that existed within the staff and organizational components of the scale. Factor analysis ultimately strengthens a measure by removing unnecessary items that either have poor factor loadings or that load on several factors simultaneously (hence not providing unique information). We first report on the factor analysis and then provide correlations for the subsequent factor structures with the established measures. We also provide the reliability and validity indicators to help establish the new scale's psychometric properties. 


\section{Factor Analysis}

An exploratory principal components factor analysis with varimax rotation and Kaiser normalization of all 55 DFFA items was conducted. As the DFFA was created to have four subscales, the analysis was constrained to four factors. The initial factor analysis showed cross-loadings of multiple items across each of the four factors. Given the face validity of the staff and organizational items as unique constructs, we then conducted separate factor analyses for staff and organizational items.

As both the staff and organization scales were designed to have two subscales - attitudes and behaviors - the analysis was initially constrained to two factors. The organization level items differentiated well across the two factors. However, a few items cross-loaded with the other factor (with loadings greater than .40). Items with factor loadings less than .40 or that were cross-loading were removed. After dropping these items, the Organizational Attitudes subscale consisted of six items and the Organizational Behaviors subscale consisted of eight items. Factor loadings ranged from .55 to .80 .

Contrary to the organizational level items, the staff level items did not differentiate well across the two factors. Examination of eigenvalues revealed the strong likelihood of a third factor. Accordingly, we reran the analysis constrained to three factors. This solution differentiated the items well and produced three solid factors. Again, items with loadings below .40 or that were cross loading were removed. Loadings for these factors ranged from .40 to .77 . Items that made up the unexpected third factor reflected specific attitudes showing preference for mothers (or females) over fathers (e.g., "Mothers are more committed to the care and well-being of their children than most fathers."). After considering these items, we named the third factor Staff Bias (SBias). While "bias" is a form of an attitude, it represents a distinct tendency to favor one condition over another, regardless of-or in the absence of-contrary evidence. The final solution yielded seven items for Staff Attitudes, six items for Staff Behaviors, and seven items for Staff Bias.

We used eigenvalues greater than one to explore whether the items written for each of the scales hung together. While eigenvalues were used as our initial cutoff, the biggest problem had to do with items that were cross loading or items that did not have convincing loadings $(>.40)$. After removing those items and identifying strong factors within the organizational and staff level items, we reran the analysis with all remaining items and constrained the solution to five factors. The remaining 34 items differentiated well across the five factors, with factor loadings ranging from .40 to .80 (see Table 1). The final 5 factor model had eigenvalues ranging from 7.09 to 1.45 and accounted for 48 percent of the variance.

\section{Reliability}

In the process of doing the factor analysis we dropped 21 of the original items, leaving a 34-item measure. Coefficient alpha for the overall 34-item scale was .87. Subscale 
Table 1

Factor Loadings

\begin{tabular}{llllll}
\hline Item & $\mathrm{OA}^{*}$ & $\mathrm{OB}$ & $\mathrm{SA}$ & SBeh & SBias
\end{tabular}

Staff believe fathers deserve same support as mothers $\quad .80$

Staff believe positive attitude needed with fathers $\quad .76$

Staff believe in facilitating father interaction $\quad .72$

Staff believe in father input $\quad .67$

Staff believe in recognizing father efforts/success $\quad .67$

Staff should involve fathers in parent-teacher meetings $\quad .62$

Total Percent Variance Accounted for by Factor $\quad 20.87$

$\begin{array}{ll}\text { Center gives staff books/resources about fathers } & .70\end{array}$

Staff recruit male facilitators $\quad .69$

Staff knowledgeable about fathering behaviors/attitudes $\quad .67$

Staff recruit fathers to parent advisory board, etc. $\quad .64$

Center provides father involvement training $\quad .63$

Center engages fathers in activities $\quad .63$

Activities accommodate fathers' time $\quad .57$

Staff identify father figure $\quad .55$

Total Percent Variance Accounted for by Factor $\quad 10.40$

Fathers should be involved in orientation $\quad .77$

$\begin{array}{ll}\text { Fathers should attend school functions } & .74\end{array}$

Program activities should include whole family $\quad .65$

Mother should involve father (even non-custodial) $\quad .58$

Mission statement should serve fathers $\quad .56$

Non-custodial fathers should get announcements $\quad .53$

Fathers have unique parenting strengths $\quad .40$

Total Percent Variance Accounted for by Factor $\quad 6.71$

$\begin{array}{ll}\text { Have fathers participate in IEP/IFSP } & .77\end{array}$

$\begin{array}{lr}\text { Have fathers sign agreements } & .75\end{array}$

$\begin{array}{ll}\text { Schedule visits with both parents } & .74\end{array}$

$\begin{array}{ll}\text { Staff give message that father's role is critical } & .58\end{array}$

$\begin{array}{ll}\text { Partnership agreements reflect father concerns } & .57\end{array}$

Recruit fathers for program assistance 4.46

Total Percent Variance Accounted for by Factor $\quad 5.63$

$\begin{array}{lr}\text { Mothers more committed to child well-being } & .66\end{array}$

$\begin{array}{ll}\text { Hard to let fathers be in charge } & .63\end{array}$

$\begin{array}{ll}\text { Assist fathers more to get things done right } & .60\end{array}$

$\begin{array}{lr}\text { Mothers more thoughtful about projects } & .59\end{array}$

$\begin{array}{lr}\text { Father feelings influenced by negative male experiences } & .55\end{array}$

$\begin{array}{lr}\text { Judge father by child's appearance } & .52\end{array}$

Don't usually interact with fathers $\quad .47$

$\begin{array}{lr}\text { Total Percent Variance Accounted for by Factor } & 4.27\end{array}$

Notes. No cross-loadings were more than .40. Please see Appendix A for full list of items.

$* \mathrm{OA}=$ Organizational Attitudes; $\mathrm{OB}=$ Organizational Behaviors; SA = Staff Attitudes;

SBeh $=$ Staff Behaviors; SBias $=$ Staff Bias 
alpha coefficients included .87 for OA, .81 for OB, .79 for SA, .80 for SB, and .71 for SBias. These reliability scores fall within the acceptable range for general reliability analysis.

\section{Interscale Correlations}

Interaction between subscale scores provides important insight into the potential for multi-colinearity and is a good indicator of validity. Each of the five subscales are moderately to strongly correlated, and, with the exception of Staff Bias, suggest a positive, significant, and supportive interaction that has similar but unique concepts (see Table 2 ). Staff bias has a significant negative correlation with the other four scales. Interscale correlations range from -.15 (Staff Bias with Organizational Behaviors) to .59 (Staff Attitudes with Organizational Attitudes), all of which are significant at the .01 level. Staff Attitudes, for example, is significantly related to Staff Behaviors $(r=.31)$, suggesting that staff who have stronger attitudes about father involvement also have stronger father-related behaviors. Given the positive correlation, those with higher Staff Attitude scores also responded in a positive manner toward their actual implementation of father-friendly behaviors. The mean response for each scale was between 3.59 (OB) and 4.56 (OA), with the exception of Staff Bias (2.31).

\section{Validity Indicators}

Construct validity is an important indicator of a measure's usefulness. It suggests that a survey is actually measuring what it intends to measure. In this case, we demonstrate validity through moderate to strong correlations with existing measures of a similar construct (called concurrent validity). For example, all five subscales were significantly correlated $(p<.01)$ with Fatherwork (FWS), Role of Father (RFQ), and Attitudes Toward Father Involvement (AFI) scales in the expected direction (see Table 2 ). Staff Bias and Organizational Attitudes were also significantly related $(p<.01)$ to the Connectedness with Father Scale (CFS). Organizational Behavior was also significantly related $(p<.05)$ to the CFS. These relationships are important because they suggest that the DFFA has a high degree of compatibility with similar concepts. Of equal importance is the notion that the correlations are not "too" high - suggesting the measure is not redundant or too similar to the other concepts (i.e., multi-colinearity is ruled out).

A measure's validity can also be assessed by comparing it with other existing measures thought to be related to the construct. It was the belief of the Head Start State Collaboration office that female staff member involvement with men in close relationships, either currently or in the past (e.g., with a spouse or partner, with their own father, etc.), would also be related to staff members' attitudes and involvement with men in Head Start settings. For this reason, we included an assessment of marital satisfaction. With the exception of Staff Bias, there was no relationship between the Dakota Father Friendly Assessment scales and Marital Satisfaction (as measured by the KMSS). In 


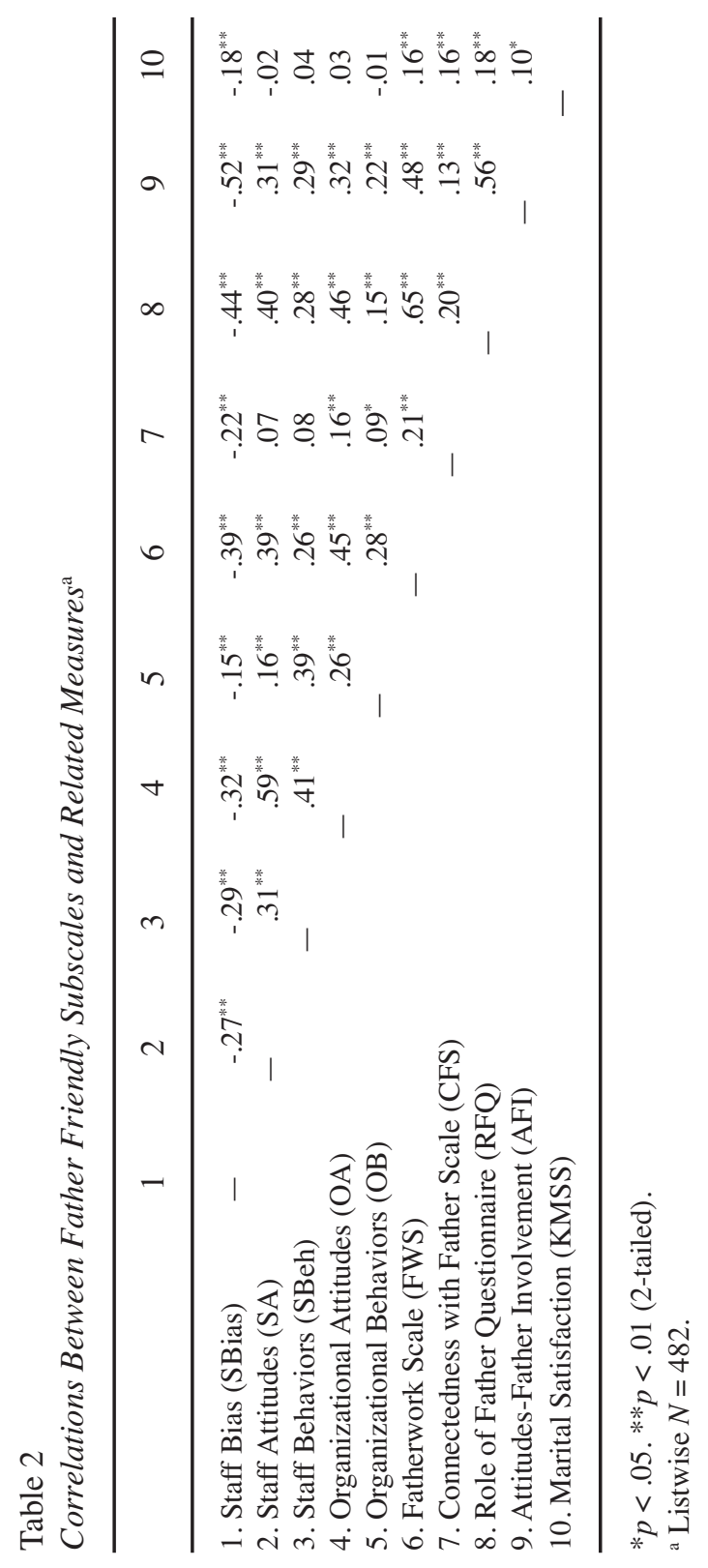


other words, staff with both high and low levels of marital satisfaction responded in similar ways to the majority of the DFFA items. This suggests that staff members' personal experiences in close relationships are not directly influencing the way they view other men's ability to be actively involved in children's lives. However, the correlation of marital satisfaction with Staff Bias $(r=-.18)$ suggests that lower satisfaction with one's own marriage may induce a preference toward mothers over fathers.

Finally, as the meaning behind the various DFFA constructs became clear, we anticipated that behaviors might lag behind perceptions of father-friendliness. Based on field experience and dialogue with Head Start staff and administrators, several layers of cognitive instruction and training are required for behavioral shifts to occur. Administrators cited numerous examples of efforts to help staff understand the value of father involvement to children during previous training sessions (over the course of several years) and noted that behaviors were slowly catching up with staff perceptions related to that particular emphasis. In order to test this ad-hoc question we simply ran a pairedsample $t$ test to identify significant differences and in what direction those differences ran. Such differences may be instructive for administrators in their efforts to support and train staff in their father involvement efforts. The paired-sample $t$ test revealed a significant difference between Staff Attitudes $(M=4.50, S D=.42)$ and Staff Behaviors $(M=3.81, S D=.55), t(607)=28.70, p<.01$. That is, average overall responses for Staff Attitudes were significantly higher than level of responses for Staff Behaviors. Organizational Attitudes $(M=4.56, S D=.43)$ were also significantly higher than Organizational Behaviors $(M=3.59, S D=.60), t(607)=36.18, p<.01$.

\section{DisCUSSION}

The development of the Dakota Father Friendly Assessment measure has focused on identifying staff perceptions of father-friendliness as related to individual attitudes and behaviors as well as the attitudes and behaviors expressed cumulatively by staff within the organization. Items were drawn from the literature and from early childhood staff, and were tailored to meet these specific areas of interest. The basic elements of developing and validating a new measure involve steps that include creating items; administering the survey; conducting factor, validity, and reliability analyses; making revisions; and exploring its utility with relevant populations. In this section we discuss the findings of our analyses and practical uses in early childhood settings.

\section{Overview of the Dakota Father Friendly Assessment as a Measure}

Ecological theory posits that interaction between parents and educators in the mesosystem is linked to interaction between parents and children at home in the microsystem (Bronfenbrenner, 1986). This is a bi-directional relationship; each system has the potential to impact the goals and outcomes of the other system. Thus, when a program is father-friendly, the goals of that program (e.g., to get fathers involved, to encourage staff members to get to know fathers/father figures, and to create environments 
that welcome men) should facilitate father-child interaction. Conversely, as fathers and children have more quality opportunities to interact with each other, fathers may feel a more valuable part of their children's lives and may increase their desire to be more actively involved not only at home, but also in their children's early childhood setting. Assessing staff attitudes, staff behaviors, organizational attitudes, and organizational behaviors should therefore be a critical step in facilitating this meaningful interaction between parents, children, and educators.

Results of the factor analysis demonstrate that the DFFA did indeed measure the four distinct constructs we intended: Staff Attitudes, Staff Behaviors, Organizational Attitudes, and Organizational Behaviors. Surprisingly, the factor analysis also revealed the presence of a fifth construct, Staff Bias. Some items originally intended to capture staff attitudes or behaviors actually captured a separate and distinct attitude, namely level of staff preference for mothers over fathers. This unintended finding brings to light an important area for examination as an organization seeks to improve the level of fatherfriendliness. Simply being aware of one's biases may facilitate change within the individual and organization.

Of potential concern is the finding that Staff Bias is strongly negatively associated with staff support of the fathering role (RFQ), the work fathers do for children (FWS), and staff attitudes toward father involvement (AFI). Staff Bias is also negatively correlated with connectedness with their own father (CFS) and marital satisfaction (KMSS). That is, those who report greater connectedness with their own father and greater marital satisfaction report lower levels of preference for mothers over fathers.

On the other hand, the correlations between the other DFFA subscales and related fathering measures provide positive feedback about how an organization is doing in their effort to be father-friendly. Staff perceptions of their attitudes and behaviors as well as that of their organization's attitudes and behaviors were highly correlated with the unique work and roles that fathers play in the lives of their children (FWS). In other words, if staff members have more supportive attitudes and behaviors toward father involvement, then they also place greater emphasis on the important contributions fathers make in the lives of their children. In addition, staff who report a strong connection with their own father (CFS) also report lower levels of Staff Bias and higher levels of Organizational Attitudes and Behaviors. According to ecological theory, for better or for worse, staff members' own lives spill over into their interaction with fathers in the early childhood setting (McBride \& Lutz, 2004).

In sum, these findings provide empirical support for the DFFA, suggesting it is a scientifically valid instrument for use in Head Start and similar settings. These correlations provide key validity indicators that suggest the survey measures what is intended, discriminates between different perspectives, and is internally consistent. The DFFA demonstrated sufficient psychometric properties to show its reliability and validity as a measure of individual and organizational levels of father-friendly functioning. This measure may assist site directors and male involvement coordinators with developing father-friendly policies within their respective organizations (e.g., Head Start/Early Head Start or similar settings). It also provides valuable insight into the level of staff 
support administrators will have as they move forward in developing supportive male involvement programs.

Staff with more supportive attitudes and behaviors toward father involvement (including less "mother/female" bias) will also place a greater emphasis on the contributions fathers make in the lives of their children. These staff members will incorporate that support into their work and are likely to be more optimistic about the contributions that fathers make in the lives of the children they serve. These staff may be more likely to follow through and make efforts to engage fathers in their children's activities. Directors want to know that the efforts and resources invested in father involvement programming won't be sabotaged by those who should be implementing it. According to ecological theory, this is the best way to meet the mutual father involvement goals of early childhood educators, administrators, fathers, and children (McBride \& Lutz, 2004).

Finally, there was an important distinction between Staff and Organizational Attitudes and Behaviors. Attitudes toward father involvement were significantly higher than the actual implementation of father-supportive behaviors. That is, stronger support for father involvement exists than for the actual implementation of fathering activities at both the individual and organizational level. This is important for administrators, directors, and program developers to know because it helps them understand that the message is getting through but the implementation of father-friendly policies and behaviors is still lacking. Given this insight, program directors may wish to visit with staff to discuss ways to host and support the implementation of specific father-child interactive activities.

\section{Implications for Practice and Research}

The DFFA demonstrates acceptable psychometric properties as a reliable and valid tool for organizations interested in measuring the pulse of their employees relative to supporting and furthering father involvement. It has implications for both applied practice and further research regarding father involvement, children, and early childhood intervention efforts. It is also valuable for practitioners and researchers interested in gaining a better conception of the ecology of Head Start.

Gaining value from the assessment process. Assessing staff attitudes and behaviors regarding father involvement in early childhood settings is designed to do more than generate additional knowledge. It is intended to: (1) highlight the critical and influential role that staff members play in establishing a father-friendly environment; (2) recognize the value that fathers and father figures contribute when they are involved in positive, meaningful ways; (3) provide a useful empirical tool that programs can use to gather information and understanding within their organization about father-friendliness; and (4) establish an assessment mechanism that enables reflective practice and the development of more father-friendly efforts and procedures. To aid programs that are interested in becoming more father-friendly, the DFFA is a tool that can guide an as- 
sessment process to gain a better understanding of how "father-friendly" staff members are in their attitudes toward the topic of father involvement. An effective assessment process allows programs to understand how staff members think and feel and it provides empirical feedback about how the organization might focus its efforts on becoming more father-friendly.

Establishing a process of becoming father-friendly as an organization. For early childhood programs to fully benefit from the DFFA, they should establish a process for becoming more father-friendly. In our efforts to provide programs with specific feedback we created a "strengths profile" that highlights an organization's strengths and growth areas using key indicators from specific areas of the survey. These indicators ranged from "fair" to "very strong" - making it easy for administrators to identify their strengths and weaknesses (White, 2005, 2006; White et al., 2003). The purpose of the "strengths profile" was not to "grade" programs on father-friendliness, but to provide feedback in the process of becoming more father-friendly. As Raikes and colleagues (2005) note, programs that are more mature in their development of a fatherfriendly environment have much greater success in reaching fathers and father figures. The areas of strength and opportunities for improvement will differ from organization to organization. Usage of the DFFA is intended to engage Head Start staff and parents in a process of reflection, evaluation, and planning in their efforts to become a program that serves the whole family, including fathers and father figures. Thus, the DFFA can be an effective tool for linking research and evaluation with practice and program implementation.

Moving from research to practice. Many staff and administrators have expressed appreciation for the "research to practice" effort reflected in the development and usage of the DFFA and subsequent training opportunities on becoming father-friendly. They value its utility in improving their father involvement efforts through the subsequent processes of assessment, reporting, and training. Efforts to build effective linkages between research and practice in the early childhood field should provide both direct and indirect feedback for staff and program administrators. This allows them to reflect on identified strengths and target growth areas with specific recommendations for change.

When feedback is shared with an early childhood program, findings can be broken down into the five specific subscales so that a "father-friendliness profile" is created. As programs receive empirical feedback and transfer findings into effective practice, the following steps will assist in moving toward an improved father-friendly profile and ultimately enhance the development and well-being of children.

- Assess baseline scores and profile to determine future direction;

- Identify existing strengths and use those strengths to anchor efforts to plan and improve;

- Target growth and improvement areas for professional development and training; and

- Create concrete steps to move forward toward an improved father-friendly environment. 
Early childhood programs can benefit in using a research-to-practice approach with a tool like the DFFA, particularly if they use the findings from the program assessment to plan incremental improvements in targeted areas. It is important to note that findings provide a snapshot of conditions at one point in time within a program, and such conditions can change and evolve significantly as attitudes and behaviors of staff are dynamic and responsive to change.

\section{Future Research and Limitations}

Future research with the DFFA should provide greater insight into its utility with differing populations and contexts. Studies that produce general assessments of Head Start staff and other early childhood settings, as well as examination of ethnicity, region, and maturity of program will further this insight. Future studies should also consider examining attitudes and behaviors prior to implementing father-involvement training and follow up on such efforts in order to assess change over time as well as level of training effectiveness. In addition, a father's actual perception and participation in an organization's male involvement program should be examined and assessed against staff and organizational attitude and behavior responses to further validate the full impact of a program's father-friendly efforts. Such research should assess change at several levels of measurement from the individual, to the father-child dyad, and within the organization in order to further determine the utility of the DFFA.

Limitations to this research include the population tested. This study was conducted in an upper Midwest region of the United States. Studies in more densely populated areas and in more diverse and cross-cultural settings would further establish the psychometric properties of the DFFA. We further believe it should be tested and applied in settings beyond Head Start, including other early childhood programs, school settings, and relevant organizational contexts. Aside from limitations specific to the population, we received only $60 \%$ of the initial surveys we mailed. This introduces the potential of a selection bias threat to external validity. However, given the confirmation from all administrators that nearly all staff completed and turned in the surveys, we are less concerned with this issue as a potential bias to this study. A final caution is warranted with respect to our correlational findings as such relationships are not causal. Longitudinal research is required to establish causation. That is, following an organization's DFFA responses over time will better determine the influence of program efforts and impact from a causal, empirical perspective.

\section{CONCLUSION}

This paper highlights the development of a new measure of father-friendliness based on staff perceptions and behaviors. The Dakota Father Friendly Assessment demonstrates the necessary psychometric properties to produce a reliable and valid measure of staff and organizational attitudes and behaviors and taps into levels of father-friendly functioning. This measure can assist early childhood program directors, staff, consultants, and other personnel in developing father-friendly policies and practices at Head 
Start, Early Head Start, other early childhood programs, and any other relevant setting that supports family services. Further, it provides valuable insight regarding current level of staff support as they develop programs for father and male involvement.

The most successful programs are those which create an ongoing "culture of fatherfriendliness" based on staff awareness of the value of a father-friendly atmosphere, efforts to create and maintain a welcoming environment for fathers as parents, and specific activities that invite fathers and father figures to be meaningfully involved in their children's lives and the programs that support them. The DFFA allows programs to focus on key indicators to increase their father-friendliness as an organization. As programs value the participation of fathers and father figures in children's lives, they assist in facilitating positive contributions to the development and well-being of the children and families they serve.

\section{REFERENCES}

Amato, P.R. (1987). Family processes in intact, one-parent, and step-parent families: The child's point of view. Journal of Marriage and the Family, 49, 327-337.

Amato, P.R., \& Rivera, F. (1999). Paternal involvement and children's behavior problems. Journal of Marriage and the Family, 61(2), 375-385.

Berger, E.H. (1995). Parents as partners in education: Families and schools working together (4th ed.). Englewood Cliffs, NJ: Prentice-Hall, Inc.

Brazelton, T.B. (1992). Touchpoints: Your child's emotional and behavioral development. Reading, MA: Perseus Books.

Brotherson, S.E., \& White, J.M. (Eds.). (2007). Why fathers count: The importance of fathers and their involvement with children. Harriman, TN: Men's Studies Press.

Brotherson, S.E., Yamamoto, T., \& Acock, A. (2003). Connection and communication in fatherchild relationships and adolescent child well-being. Fathering, 1(3), 191-214.

Cowan, P.A., Cowan, CP., Pruett, M.K., Pruett, K., \& Wong, J.J. (2009). Promoting fathers' engagement with children: Preventive interventions for low-income families. Journal of Marriage and Family, 71, 663-679.

Cunningham, B. (2000). The good business of being father-friendly: Does your center welcome male customers. Child Care Information Exchange, 135, 70-71.

Davidov, M., \& Grusec, J.E. (2006). Untangling the links of parental responsiveness to distress and warmth to child outcomes. Child Development, 77, 44-58.

Fagan, J. (1999). Predictors of father and father figure involvement in pre-kindergarten Head Start. National Center on Fathers and Families. Retrieved July 3, 2006 from http://www.ncoff.gse.upenn.edu/wrkppr/faganpaper.pdf

Fagan, J., \& Iglesias, A. (1999). Father involvement program effects on fathers, father figures, and their Head Start children: A quasi-experimental study. Early Childhood Research Quarterly, 14(2), 243-269.

Fagan, J., Newash, N., \& Schloesser, A. (2000). Female caregivers' perceptions of fathers' and significant adult males' involvement with their Head Start children. Families in Society, 81, 186-196.

Fagan, J. (2008). Randomized study of a pre-birth coparenting intervention with adolescent and young fathers. Family Relations, 57(3), 309-323. 
Garinger, J., \& McBride, B.A. (1995). Successful parental involvement strategies in prekindergarten at-risk programs: An exploratory study. The School-Community Journal, 5, 59-77.

George, J.M., \& Jones, G.R. (2008).Understanding and managing organizational behavior (5th Ed.). Upper Saddle River, NJ: Pearson Prentice Hall.

Graves, L.M., Ohlott, P.J., \& Ruderman, M.N. (2007). Commitment to family roles: Effects on managers' attitudes and performance. Journal of Applied Psychology, 92(11), 44-56.

Hawkins, A.J., \& Dollahite, D.C. (Eds.). (1997). Generative fathering: Beyond deficit perspectives. Thousand Oaks, CA: Sage.

Hawkins, A.J., Dollahite, D.C., \& Brotherson, S.E. (1997). Fatherwork: A conceptual ethic of fathering as generative work. In A.J. Hawkins \& D.C. Dollahite (Eds.), Generative fathering: Beyond deficit perspectives (pp. 17-35). Thousand Oaks, CA: Sage.

Holmes, E.K., Galovan, A.M., Yoshida, K., \& Hawkins, A.J. (2010). Meta-analysis of the effectiveness of resident fathering programs: Are family life educators interested in fathers? Family Relations, 59(3), 240-252.

Horn, W.F. (2004). Head Start's fatherhood focus. Head Start Bulletin, 77, 2-3. Washington, DC: Head Start Bureau, Administration on Children, Youth and Families, U.S. Department of Health and Human Services.

Knoester, C., \& Eggebeen, D.J. (2006). The effects of the transition to parenthood and subsequent children on men's well-being and social participation. Journal of Family Issues, 27, 15321560 .

Koester, R., Franz, C., \& Weinberger, J. (1990). The family origin of empathic concern: A 26year longitudinal study. Journal of Personality and Social Psychology, 58(4), 709-717.

Lamb, M.E. (1975). Fathers: Forgotten contributors to child development. Human Development, $18,245-266$.

Levine, J.A. (1993). Involving fathers in Head Start: A framework for public policy and program development. Families in Society, 74, 4-19.

Lewis, C. (1997). Fathers and preschoolers. In M.E. Lamb (Ed.), The role of the father in child development ( $3^{\text {rd }}$ ed., pp. 121-142). New York: John Wiley \& Sons, Inc.

McAllister, C., Wilson, P., \& Burton, J. (2004). From sports fans to nurturers: An early Head Start program's evolution toward father involvement. Fathering, 2(1), 31-59.

McBride, B.A., \& Lutz, M.M. (2004). Intervention: Changing the nature and extent of father involvement. In M.E. Lamb (Ed.), The role of the father in child development (4th ed.). New York: Wiley.

McBride, B.A., \& Rane, T.R. (1996). Father/male involvement in early childhood programs. ERIC Digest. Urbana, IL: Educational Resources Information Center (ERIC).

McBride, B.A., \& Rane, T.R. (2001). Father/male involvement in early childhood programs: Training staff to work with men. In J. Fagan \& A.J. Hawkins (Eds.), Clinical and educational interventions with fathers (pp. 171-190). Binghamton, NY: Haworth Clinical Practice Press.

McBride, B.A., Rane, T.R., \& Bae, J. (2001). Intervening with teachers to encourage father/male involvement in early childhood programs. Early Childhood Research Quarterly, 16, 77-93.

McFarland, L. (2000). Involving fathers in the preschool classroom. Texas Child Care, 24(2), 27.

Nord, C.W., Brimhall, D., \& West, J. (1997). Fathers' involvement in their children's schools. Washington, DC: U.S. Department of Education, Office of Educational Research and Improvement.

Notaro, P.C., \& Volling, B.L. (1999). Parental responsiveness and infant-parent attachment: A replication study with fathers and mothers. Infant Behavior and Development, 22, 345-352. 
Palkovitz, R. (1984). Parental attitudes and fathers' interactions with their five-month-old infants. Developmental Psychology, 20, 1054-1060.

Palkovitz, R., Copes, M.A., \& Woolfolk, T.N. (2001). "It's like ... You discover a new sense of being": Involved fathering as an evoker of adult development. Men and Masculinities, 4, 4969.

Palm, G.L. (2006). The developmental journey: Fathers and children growing together. In S.E. Brotherson \& J.M. White (Eds.), Why fathers count (pp. 163-176). Harriman, TN: Men's Studies Press.

Parke, R.D. (1996). Fatherhood. Cambridge, MA: Harvard University Press.

Pruett, K. (2001). Fatherneed: Why father care is as essential as mother care for your child. New York: Broadway Books.

Raikes, H., \& Bellotti, J. (2006). Two studies of father involvement in Early Head Start programs: A national survey and a demonstration program evaluation. Parenting: Science \& Practice, 6(2/3), 229-242.

Raikes, H.H., Boller, K., van Kammen, W., \& Summers, J. (2002). Father involvement in early Head Start programs: A practitioners study. Lincoln, NE: University of Nebraska.

Raikes, H.H., Summers, J.A., \& Roggman, L.A. (2005). Father involvement in early Head Start programs. Fathering, 3(1), 29-58.

Ramirez-Valles, J., Zimmerman, M.A., \& Juarez, L. (2002). Gender differences of neighborhood and social control processes: A study of the timing of first-intercourse among low-achieving, urban, African American youth. Youth \& Society, 33, 418-441.

Schumm, W.R., Paff-Bergen, L.A., Hatch, R C., Obiorah, F.C., Copeland, J.M., Meens, L.D., et al. (1986). Concurrent and discrimant validity of the Kansas Marital Satisfaction Scale. Journal of Marriage and the Family, 48(2), 381-387.

Taylor, A.R., \& Machida, S. (1994). The contribution of parent and peer support to Head Start children's early school adjustment. Early Childhood Research Quarterly, 9, 387-405.

Vann, N., \& Nelson-Hooks, J. (2000). Father-friendliness organizational self-assessment and planning tool. Retrieved May 8, 2007 from http://www.nhsa.org/program/fathers/ parents_father_assess.htm

White, J.M. (2005, October). Father friendly assessment profiles for the Nebraska Head Start/Early Head Start Association. Evaluation and analyses report to the Nebraska State Head Start Association Board, Lincoln, NE.

White, J.M. (2006, September). Father friendly follow-up assessment profiles for the Wichita Falls, Texas Head Start/Early Head Start Association. Follow-up evaluation and analyses report to the Wichita Falls, Texas, Head Start Association, Wichita Falls, TX.

White, J.M., Brotherson, S.E., Kampmann, J.A., Arne, S. M., Iverson, M.A., \& Cowan, J.J. (November 2003). Father friendly survey: Report \#2: Report for the Head Start/Early Head Start father friendly assessment: South Dakota Region VIII and Region XI Grantees. South Dakota State University, Technical Report to the Head Start State Collaboration Office, Pierre, SD.

Zigler, E., \& Styfco, S. (2000). Pioneering steps (and fumbles) in developing a federal preschool intervention. Topics in Early Childhood Special Education, 20(2), 67-70, 78. 


\section{APPENDIX A \\ DAKOtA FATHER FRIENDLY AsSESSMENT}

Our program's mission statement should include services to fathers/father figures

Fathers should be involved in the orientation and enrollment process

It is important that fathers attend school functions

It is important to have program activities for the whole family

*Program projects and activities don't always need to appeal to men

*Fathers typically have less preparation or guidance in becoming parents than do mothers

Mothers are more committed to the care and well-being of their children than most fathers

Fathers bring unique strengths to parenting that meet a child's growth and development needs

*Balancing work and family often makes it hard for fathers to be as involved as they should be

*A father's involvement has little to do with the relationship with the child's mother

Mothers put more thought into program projects and activities

I find it hard to let fathers be in charge after assigning them a task

*A mother's effort to correct or change a father's behavior can limit his involvement

*A mother should be encouraged to have the father involved, even if they don't live together

Fathers not living in the home should also be sent announcements of program activities

My feelings about the value of fathering has been influenced by negative experiences with men

I encourage mothers to support fathers, even if involvement isn't desired (abuse cases omitted)

*I encourage fathers to volunteer in classroom or home-based activities

I actively recruit fathers for assistance with program services

*When I facilitate family goal setting activities, the father is seldom involved

*When fathers drop off children I make an effort to greet them warmly

I usually don't interact with fathers who come with mothers

*When calling a family, I tend to ask for the mother when the father answers the phone

I make an effort to have fathers sign family partnership agreements

I make an effort to have fathers take part in the IEP or IFSP process

I try to schedule home visits when both parents are available

The message I give to fathers is that their role is critical to their child's development

Partnership agreements reflect the father's interests \& concerns as well as the mother's

During program projects, I tend to assist fathers more so they get things done the way I want them

I tend to judge how good a father is by his child's appearance

All Head Start staff at our center believe in the need for a positive attitude toward working with fathers

All Head Start staff at our center believe they should provide the same support for fathers as mothers

All staff at our center believe they should provide recognition for fathers' efforts and successes

All of our staff believe it is important to facilitate interaction with fathers

All of our staff believe fathers should participate in scheduled parent-teacher meetings

All of our staff believe input should be sought from fathers about what they want from Head Start

*There are some staff in our center who have personal biases toward fathers and males in general

*All of our staff value the capacity for nurturing that is present in fathers

* My own attitude toward father involvement has been or is influenced by other staff

*When compared to other priorities, most staff believe that father involvement should not be at the top

* Our Head Start center has a responsibility to encourage fathers to interact with their children

Our Head Start center provides regular training on father involvement (at least semiannually)

Our Head Start center provides staff with books and resources for and about fathers

All of our staff are knowledgeable about fathering behaviors and attitudes

*All of our staff use curriculum materials that portray men in a positive manner

*All of our staff treat fathers in a respectful and supportive manner

*Our Head Start center offers few program options for fathers and their specific needs

Our staff actively recruit male staff members and facilitators for father's events/groups

Our staff actively recruit fathers for the parent advisory board, board of directors, etc

Our center's approach to father involvement has tried to engage most fathers in program activities

All staff try to identify a primary father figure to encourage involvement in the child's life

*Father involvement activities are regularly scheduled to accommodate the time constraints of fathers

* Many staff are not aware of little things they do that unintentionally exclude fathers

* Most staff find it difficult to involve fathers in program activities

*For most staff, the effort required to facilitate father involvement is a significant source of job stress
SA A N D SD

SA A N D SD

SA A N D SD

SA A N D SD

SA A N D SD

SA A N D SD

SA A N D SD

SA A N D SD

SA A N D SD

SA A N D SD

SA A N D SD

SA A N D SD

SA A N D SD

SA A N D SD

SA A N D SD

SA A N D SD

SA A N D SD

SA A N D SD

SA A N D SD

SA A N D SD

SA A N D SD

SA A N D SD

SA A N D SD

SA A N D SD

SA A N D SD

SA A N D SD

SA A N D SD

SA A N D SD

SA A N D SD

SA A N D SD

SA A N D SD

SA A N D SD

SA A N D SD

SA A N D SD

SA A N D SD

SA A N D SD

SA A N D SD

SA A N D SD

SA A N D SD

SA A N D SD

SA A N D SD

SA A N D SD

SA A N D SD

SA A N D SD

SA A N D SD

SA A N D SD

SA A N D SD

SA A N D SD

SA A N D SD

SA A N D SD

SA A N D SD

SA A N D SD

SA A N D SD

SA A N D SD

SA A N D SD

Notes. Please contact the lead author for permission and information on using the scale.

*Denotes items removed from the scale after refining the 5 -factor model following factor analysis. 